\title{
Theoretical and Practical Aspects of Electrical Equipment Eco-Design
}

\author{
Ovidiu Tsutsuianu \\ Energy and Environment Department, Romanian National Committee of the World Energy Council, Bucharest, Romania
}

\section{Email address:}

ovidiu.tutuianu@gmail.com

\section{To cite this article:}

Ovidiu Tsutsuianu. Theoretical and Practical Aspects of Electrical Equipment Eco-Design. Engineering Science.

Vol. 4, No. 4, 2019, pp. 59-64. doi: 10.11648/j.es.20190404.12

Received: June 26, 2019; Accepted: July 30, 2019; Published: December 20, 2019

\begin{abstract}
In the last time some factors and especially the environmental protection requirements have forced to add the ecological criterion for design of electrical equipments, within a new Eco-design concept. The essence of this concept consists in the integration of environmental aspects at project phase, taking into account full life cycle of product. The work presents some theoretical and practical aspects of Eco-design for electrical equipments. Relationship between environmental management systems and Eco-design is underlined. Some key indicators for measuring the environmental performances are exemplified. The actual eco-design conception combines Qualitative Assessment of Life Cycle Criteria with a quantitative method based on the Product Carbon Footprint. The calculation of the last indicator means the quantification of the greenhouse gases emissions ( $\mathrm{kgCO}_{2}$ equivalent) during the life cycle of products and services. The maintenance and repairs activities of electrical equipments have also some negative impacts on environment (directs and indirect). The author proposed, as an original contribution, two relevant environmental performance indicators in this field: 1 . The absolute indicator $\left(E_{s}\right)-\mathrm{CO}_{2}$ emission involved into service [ $\left.\mathrm{kg} \mathrm{CO}_{2}\right] ; 2$. The relative indicator $\left(e_{s}\right)-\mathrm{CO}_{2}$ specific emission involved into service [ $\mathrm{kg} \mathrm{CO} \mathrm{CO}_{2} /$ euro]. These indicators assist the companies to find the losses and to establish the efficient corrective and preventive actions, to complete environmental data base and to compare the environmental performance between different management levels. The main advantages of eco-design application are: Creativity and innovation; Low manufactured costs; Superior quality of the product; More guarantees; "Green is better sold".
\end{abstract}

Keywords: Eco-design, Electrical Equipment, Environmental Requirements, Life Cycle of Product/Service, Product Carbon Footprint, $\mathrm{CO}_{2}$ Emission, Environmental Performance Indicator

\section{Introduction}

Few years ago, two main criteria (cost and reliability into operation) have been considered for electrical equipments design. In the last time, some factors determined even in this sector to add the ecological criterion within a new Eco-design concept. The essence of Eco-design consists in the integration of environmental aspects at project phase taking into account full life cycle of product, from raw materials acquisition up to product elimination. The particle "eco" means at the same time economy and ecology [1].

\section{Influence Factors of "Eco-Design"}

"Eco-design" is influenced by some factors shown in the "Figure 1", namely:

\subsection{Legislation}

The globalization of world economy obliged the companies from each country to participate within a large context of regulation and standardization in the energy/environment field. Are mentioned in this respect: "Montreal Protocol", "KyotoProtocol", "Environmen-tal European Standards", "Environmental International Standards" (especially ISO 14000 series), as well as specific regulation for electrical equipments, such as, European Directives WEEE-2 012/19/EU and RoHS-2 011/65/EU [2-6]. Important are also the national regulations in the field [7].

\subsection{Market Requirements}

Because, "environmentally friendly products" (including 
electrical equipments) are encouraged on market competition, they are profitable not only for consumers but for producers too.

\subsection{Economical Requirements}

Specific environmental requirements may be balanced to prevent supplementary capital costs (investments). For example, an "Eco-design" which provides less raw materials or energy consumptions can obtain a low total cost. According with life cycle concept, this kind of design can be considered like economically.

\subsection{Specific Environmental Requirements}

Respecting these specific requirements can be reduced significantly environmental negative impacts associated with electrical equipments on their full life cycle [8].

\subsection{Social Aspects}

The electrical products of "Eco-design" can win an easy acceptance from the large public. In this field already are some successes in applying the new design concept. This matter can have a profitable influence about of society [9].

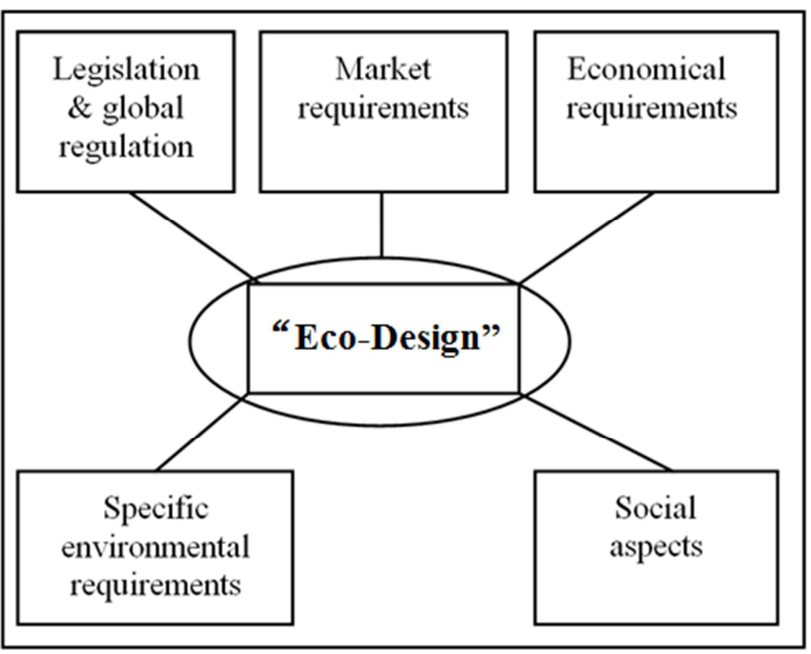

Figure 1. Factors of "Eco-design" [9].

\section{Relationship Between Environmental Management Systems and "Eco-Design"}

In accordance with EMAS-communitarian environmental management and audit scheme [10] or with ISO 14001: 2015, environmental management systems are based on "clean" production techniques/technologies having in this respect some common points with "Eco-design". Therefore, one environmental management system, implemented and certified is a good starting point for products "Eco-design" approaching.

Key indicators for measuring the environmental performances base on "production units". This kind of indicators can have in the view energy, water, chemical matters consumptions or the quantity of eliminated hazardous wastes reported to:

1. "Surface $\left[\mathrm{m}^{2}\right]$ of recorded circuit" (for recorded circuit producers);

2. "Surface $\left[\mathrm{m}^{2}\right]$ of silicon" (for semiconductor producers);

3. "Component" (for passive components producers);

4. "Product" (for original equipments producers) [11].

Within a company can't be a single "eco-designer" because the "eco-design" requires one interdisciplinary work approach For this reason there are much more "entering points" for "Eco-design":

a) Supply Department is responsible for dealers selection and for acquisition of components with low contents in hazardous matters;

b) Marketing Department will identify the market opportunities from category "green is sold better" and will promote "green efforts" of company;

c) Research and Development Department will take into account environmental aspects like a creative tool for innovation and for identification of efficient possibilities;

d) Environmental Department and Health \& Safety Labour Department will have their specific contribution from environmental protection and respectively, labour security point of view;

e) Quality Department has missions regarding better products achievement, which gives to him one special place within "Eco-design";

f) Designer or Design Team if already works within an interdisciplinary framework will have environmental performance only like a supplementary decisional criterion to aide at yours daily activity.

\section{4. "Eco-Design" Stages}

"Eco-design" stages with adequate activities are guided by International Standard ISO/TR 14062/2002 [12] and include:

\subsection{Planning (Design Ideas)}

a) To collect data/proofs; To select these in accordance with benefits and reliability; To line their at corporate strategy;

b) To take into account "environmental aspects"; To think "life cycle"; To define "environmental requirements;

c) To analyse external factors; to choose adequate approach of environmental projects; to check selected approach;

d) To perform an "environmental analyse" of referential product.

\subsection{Draft Project (Project Outlook)}

a) To set common idea; To perform an "analyse orientated to life cycle"; To define "measurable tasks";

b) To develop design concept; To fulfil "environmental requirements"; 
c) To materialize within a "specification" and to apply the results from the "analyse of referential product".

\subsection{Detailed Design (Project Solutions)}

a) To apply project approach;

b) To finalize "product specifications ", including "life cycle" considerations: using "Eco-design" instruments and data base; searching alternatives for materials with problems; elaborating scenarios regarding "life cycle" for a better understanding of product evolution; analysing assemblies / disassemblies.

\subsection{Checking/Prototype (Prototype)}

a) To check specifications by prototypes testing;

b) To analyse considerations regarding prototype "life cycle": doing comparison with previous generation of products; analysing objectives achievement.

\subsection{Production Launching on the Market (Product)}

a) To publish communications regarding "environmental aspects", the best utilization and elimination of product;

b) To take into consideration possible "environmental statement" and its requirements: promoting to clients groups "environmental excellence" of product; underlining supplementary characteristics: quality, costs during utilization; making the users for "green products".

\subsection{Product Analyse}

a) To take into consideration and to evaluate experiences, environmental aspects and impacts: evaluating product success (what arguments really trusted for clients?); identifying possibilities on later improvement for future generation of products; what innovations will appear (within company or on market)? What are doing the competitors?

\section{An "Eco-Design" Strategy}

Products optimisation and redesigning are based on $6 \mathrm{RE}$ philosophy:

1. RE-thinking of product and his functions (for example, how can be efficiently used the product);

2. RE-duction of materials and energy consumption during its "life cycle";

3. RE-placement of hazardous substances with "environ-mental friendly" alternatives;

4. RE-cycling. It chooses materials which can be recycled and the product is thought thus so that can be easy disassembly for recycling;

5. RE-using. The product is designed thus so that theirs component parts to be reused;

6. RE-covering (repairing). It thinks one easy repaired product, thus so that he doesn't be too quickly replaced.
Initially it was applied 3RE philosophy (recycling, reusing and recovering). Further, "Eco-design" strategy can be focused on the following steps:

a) To check current stage of products: what market requires, what expectations have the client, what is manufactured within company up to now?

b) To identify environmental aspects: which are the relevant environmental aspects of products?

c) To establish objectives and to improve them;

d) To involve departments and suppliers chain;

e) To choose the instruments, checking lists and appropriate guides; to determine the relationship between environmental arguments and costs;

f) To make an analyse of product and to identify potential for improvement;

g) To promote innovation aspects [1].

\section{6. "Eco-Design" Practice}

\section{A. Selection of materials}

"Eco-design" concept application means a processional chain according to flow chart shown in "Figure 2". [9].

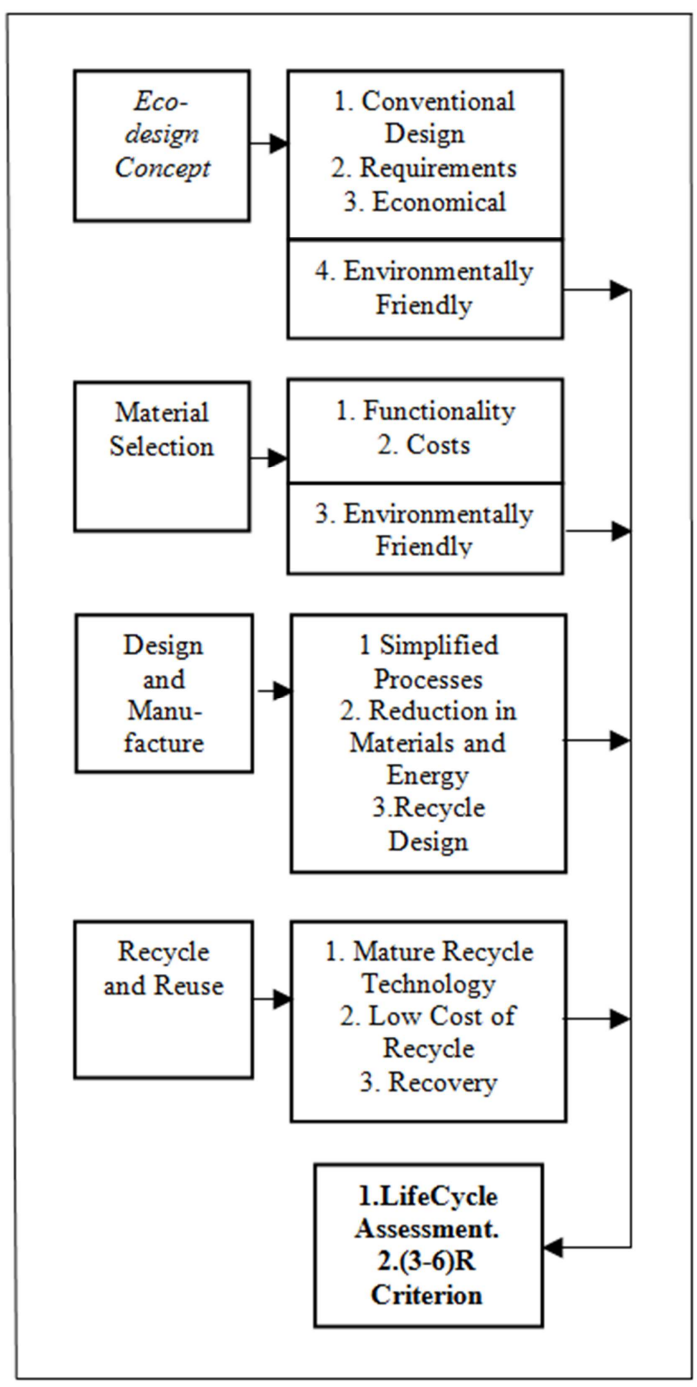

Figure 2. Environmentally friendly design process. 


\section{B. "Environmentally friendly" insulation materials}

Evaluation of environmental negative impacts generated by electrical equipments is possible by integration of environmental aspects into product design and development [8]. The environmental impacts should be quantified during all stages of material life cycle: manufacture, utilization, and disposal. Some organisms from environmental field (such as, EIME/Environmental Information and Management Explorer, from France) developed software which is used to assess environmental impacts generated by electrical equipments [13].

One material can be considered like "environmentally friendly" if he meets firstly, the "3 R criterion", and namely:

a) Can be easily recycled using a technology commercially available with minimum costs;

b) So that after reprocessing their characteristics meet further regulated requirements;

c) Can be recovered (can reduce of other raw materials consumption by recovery, including repairs of some product/equipment components within is incorporated).

C. Design for "recycle" and "reuse"

A typical design principle for easy recycle and reuse consists of two elements: avoid the use of components made of mixed materials or use single type of materials.

The key to achieve such kind of design can be considered:

a) Avoiding the use of metal reinforced plastic components;

b) Avoiding the use of metal bolts and nuts and try to promote locking features of the plastic materials;

c) Avoiding the use of glue to prevent environmental pollution during recycling;

d) Using the same type and grade of materials. When this is not possible, should be clearly mark and classify the materials;

e) Avoiding the use of decorating materials, words, paints and protective coatings;

Many years recycling and reusing focused on plastic materials by three methods:

1. Mechanical method

This method is applied for large components, such as external shields and insulation meshes. It involves: classification, decommissioning, identification and pulverising etc.

2. Chemical method

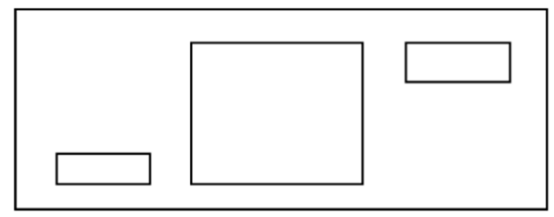

A

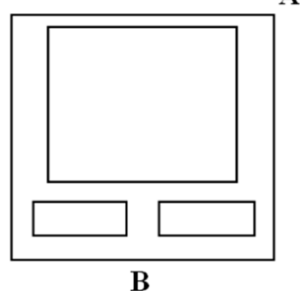

Figure 3. Diverse manners for switchgear packaging: A).Classical packaging; B). "Environmentally friendly" packaging.
For products of smaller volume, achieved from different materials, their separation isn't easily. In this case can be used a chemical approach, like high temperature decomposition or incineration.

3. Direct conversion

For materials that cannot be reprocessed by the above mentioned methods, direct burning can be used. Although, the application of this method needed a carefully checking of pollutant emission resulted by combustion, it is also a positive environmental impact consisting in fossil fuel saving (especially oil and natural gas).

\section{Reduction in the use of materials}

To reduce raw materials consumption for electrical products can be take into consideration many aspects. According to "Figure 3" [9], a change in the packaging design of switchgear can significantly reduce the mass of packaging materials.

Table 1. Comparison of "Design A and B" [9].

\begin{tabular}{llll}
\hline Materials & Unit & Design A & Design B \\
\hline Timber & $\mathrm{kg}$ & 15 & 10 \\
Plastic & $\mathrm{kg}$ & 6 & 4 \\
Paper & $\mathrm{kg}$ & 3 & 2 \\
\hline
\end{tabular}

From Design A to Design B, a one third volume reduction is achieved. In Table 1, the changes regarding design concept of packaging are quantified.

The actual eco-design conception combines Qualitative Assessment of Life Cycle Criteria with a quantitative method based on the Product Carbon Footprint. The calculation of the last indicator means the quantification of the greenhouse gases emissions $\left(\mathrm{kgCO}_{2}\right.$ equivalent) during the life cycle of products and services [14].

The "state of the art" in the eco-design field is includes in the book from reference [15]. This book considers eco-design, a major tool for reducing the environmental impacts of products, services and systems in the context of sustainable development. It covers four key aspects of eco-design, applied to electric engineering.

First, it describes current and future methodologies and standards, including regulations, which apply to electric engineering.

In turn, the second chapter is devoted to energy systems and planning, including constraints on the insertion of equipment into the grid. Components such as transformers and cables, their eco-design characteristics and impacts, and their potential to improve the environmental impacts of networks are described in the third chapter.

Lastly, the fourth chapter deals with materials in terms of their performance and ecological impact. In the case of electric equipments, the eco-design approach is also connected to the development of renewable energies and energy efficiency.

\section{Practical Aspects of Eco-Design to the Maintenance of Electrical Equipments}

The maintenance activity of industrial equipments, as 
phases of products life cycle, have also some negative impacts on environment (directs and indirect). From the study of the technical literature and its own practical work, the author has found that "maintenance", one of the phases of the life cycle of electrical equipment, is not sufficiently analyzed and quantified in terms of negative impacts on the environment, including $\mathrm{CO}_{2}$ emissions involved in the service performed [16-19].

In the work [20], author proposed two indicators for environmental performance evaluation into maintenance activity of industrial equipments, namely: 1. The absolute indicator (E-s) $\mathrm{CO}_{2}$ emission involved into service [ $\left.\mathrm{kg} \mathrm{CO} \mathrm{CO}_{2}\right]$;

2. The relative indicator (e-s)-CO $\mathrm{CO}_{2}$ specific emission involved into service [ $\mathrm{kg} \mathrm{CO} /$ euro].

The first indicator results from a "power approach" of the "environmental balance" which allows the calculation of "energy involved into service" $\left(\mathrm{W}_{\mathrm{s}}\right)$. This energy is turn into "equivalent fuel" $\left(\mathrm{B}_{\mathrm{s}}\right)$ and finally into " $\mathrm{CO}_{2}$ emission involved into service" $\left(\mathrm{E}_{\mathrm{s}}\right)$. The second ones results by division of $\left(E_{s}\right)$ to the "total financial value of maintenance service" $\left(\mathrm{V}_{\mathrm{s}}\right)$, expressed in euro. A practical application for calculation of these indicators in the case of two power transformers was made.

According to the calculation methodology presented above, the comparison indicators $\mathrm{W}_{\mathrm{s}} ; \mathrm{E}_{\mathrm{s}} ; \mathrm{V}_{\mathrm{s}}$ and $\mathrm{e}_{\mathrm{s}}$ are shown in "Table 2".

Table 2. Elements of "environmental "comparison" [20].

\begin{tabular}{lll}
\hline \multirow{2}{*}{ Indicators } & $\begin{array}{l}\text { Transformer 250 kVA, } \\
\mathbf{2 0 / 0 . 4} \mathbf{~ k V} \text { repair }\end{array}$ & $\begin{array}{l}\text { Transformer 16 MVA, } \\
\mathbf{1 1 0 / 2 2} \mathbf{~ k V} \text { repair }\end{array}$ \\
\hline $\mathrm{W}_{\mathrm{s}}[\mathrm{GJ}]$ & 46.7 & 1070.5 \\
$\mathrm{E}_{\mathrm{s}}\left[\mathrm{kg} \mathrm{CO}{ }_{2}\right]$ & 4954.7 & 113468.3 \\
$\mathrm{~V}_{\mathrm{s}}[\mathrm{euro}]$ & 3343 & 168182 \\
$\mathrm{e}_{\mathrm{s}}\left[\mathrm{kgCO}_{2} /\right.$ euro $]$ & 1.482 & 0.675 \\
\hline
\end{tabular}

$\left(E_{s}\right)$ puts in evidence only absolute value of environmental aspects, but $\left(\mathrm{e}_{\mathrm{s}}\right)$ is more relevant because shows practically, with what environmental impact $(\mathrm{kg} \mathrm{CO})$ is obtained each monetary unit (1euro), accordingly with performed service.

These indicators assist the companies to find the losses and to establish the efficient corrective and preventive actions, to complete environmental data base and to compare the environmental performance between different management levels.

\section{Conclusion}

1. Eco-design is a current practice absolutely necessary.

2. To be truly effective, is needed as involved $\mathrm{CO}_{2}$ emissions (carbon footprint) to be correctly assessed in all phases of the life cycle of products or services, including in the maintenance phase.

3. The advantages of eco-design application are: Creativity and innovation; Low manufactured costs; Superior quality of the product; More guarantees; "Green is better sold".

4. The proposed indicators from this paper can by used on different organizational levels, having two main advantages:

a) To assist the Management to find all category of losses (raw material, natural resources, energy) and to take efficient corrective and preventive actions;

b) To complete environmental protection data base and to compare environmental performance on different level of maintenance services.

\section{References}

[1] Schischke, K., Hageluken, M., Steffenhagen, G. Eco-Design Awareness Raising Campaign for Electrical \& Electronics SMEs. Fraunhofer IZM Berlin, Germany, 2014.

[2] Directive 2012/19/EU on the wastes from electrical and electronic equipment (transposed into Romanian legislation by Government Emergency Ordinance/GEO no. 5/2015).

[3] Directive 2011/65/EU on the restriction of the use of certain hazardous substances in electrical and electronic equipment (transposed into Romanian legislation by GEO no. 322/2013 and no. 234/2019).

[4] SR EN ISO 9001: 2015. Quality management systems. Requirements. ASRO, Bucharest (In Romanian).

[5] SR EN ISO 14001: 2015.Environmental management systems. Requirements. ASRO, Bucharest (In Romanian).

[6] ISO 45 001: 2018. Occupational health and safety management systems. Requirements. ASRO, Bucharest (In Romanian).

[7] Legislation and environmental regulations. Information and Documentation Office for the Environment Infoterra, 2003, Bucharest (In Romanian).

[8] SR EN ISO 14040: 2007 (Romanian version). Environmental management. Life cycle assessment. Principles and framework. ASRO, Bucharest, Second Edition, June 2008.

[9] Wenjie, Qi., Shengtao, Li., Falkingham, Leslie., Hassanzadeh Mehrdad., James, Ian. Environmentally Friendly Design for Electrical Insulation System. State Key Laboratory of Electrical Insulation and Power Equipment, Xi'an Jiaotong University, Xi'an 710049.

[10] Regulation (EC) No. 1221/2009 of the European Parliament and of the Council of 25 November on the voluntary participation by organisations in a Community eco-management and audit scheme (EMAS)

[11] Tsutsuianu, O. (2006); (2011) Environmental Performance Evaluation and Reporting. Environmental Indicators. AGIR Press, Bucharest (In Romanian).

[12] SR ISO/TR 14062/2008 (Romanian version). Environmental management. Integrating environmental aspects into product design and development. ASRO, Bucharest, First Edition, September 2008 .

[13] Environmental Information and Management Explorer (EIME), 2014.

[14] Sanyé-Mengnal, E., Lozano, R.G., Farreny, R., Oliver-Solá, J., Gasol, C., Rieradevall, J. Introduction to the Eco-Design Methodology and Role of Product Carbon Footprint. Vol.1 (pp.1-24) Springer, 2014. 
[15] Bessède J. L. Eco-Design in Electrical Engineering. Springer International Publishing AG, Cham, Switzerland, 2018.

[16] Romanian Government Decision no. 1043/2007 on eco-design requirements for energy-using products. The Official Gazette of Romania, 12.09.2007. (In Romanian).

[17] Pralea, J. Ecological materials used in eco-design. (In Romanian). UAGE Iassy-Romania, 2019.
[18] Amza, G. Eco-technology. Printech, Bu- charest, 2007. (In Romanian).

[19] Vasilescu, E. Eco-design of processes in materials engineering. AGIR Bulletin, no. 1, 2017, pp. 166-170. (In Romanian).

[20] Tsutsuianu, O. Environmental Performance Indicators into Maintenance Activity of Industrial Equip-ments.' Calitatea, acces la success", ["The quality, access to success"-Romanian Magazine] 2015, no. 144, pp. 91-93 (In English).

\section{Biography}

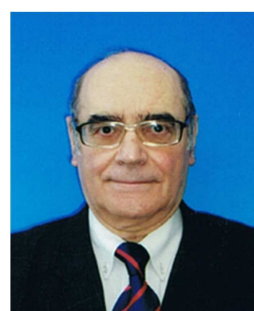

Ovidiu Tsutsuianu graduated from the Faculty of Energy from the Polytechnic University of Bucharest-PUB (1965). Master's degree: in "economic engineering" at PUB; in "sustainable development management" at Nijenrode University (Holland). Specializations on "energy and environment" in: Germany, Holland, China, USA. Management and control positions in the Ministry of Electricity and power companies: RENEL, CONEL, TRANSELECTRICA. Associate teacher at the PUB and at the Bucharest Academy of Economic Studies. Member in the Environment Specific Committee of UNIPEDE/EURELECTRIC, Paris/Bruxelles (1992-2000). UNIDO's expert on Energy \& Environment (since 1992). Currently, he is counsellor at the Romanian National Committee of World Energy Council. 